\title{
Medicolegal aspects of neoplastic dermatology
}

\author{
A Neil Crowson \\ Departments of Dermatology, Pathology, and Surgery, University of Oklahoma and Regional Medical \\ Laboratory, St John Medical Center, Tulsa, OK, USA
}

\begin{abstract}
Medical malpractice litigation is rising at an explosive rate in the US and, to a lesser extent, in Canada. The impact of medical malpractice litigation on health care costs and the cost of insurance is dramatic. Certain specialist categories are becoming uninsurable in some parts of the US, while in others, clinicians are retiring early, restricting or changing practice or changing states of residence in consequence of medical malpractice claims and of the cost and availability of insurance. This, in turn, has had the real effect of denying care to patients in some communities in the US. Some $13 \%$ of all medical malpractice claims relate to one area of neoplastic dermatopathology, specifically, melanocytic neoplasia. Certain steps can be taken by pathology laboratories to reduce, but never completely eliminate, the risk of medical malpractice claims. In this review, attention is paid to the source of medical malpractice claims and an abbreviated approach to specific strategies for risk management is presented.

Modern Pathology (2006) 19, S148-S154. doi:10.1038/modpathol.3800518
\end{abstract}

Keywords: malpractice; dermatopathology; risk management; case review

Medical malpractice claims and settlements have skyrocketed across the US. Some malpractice insurers are no longer covering physicians, ${ }^{1}$ and the issue of uninsured physicians leaving medical practice has impacted a broad array of specialties and become a major political issue at the state and national levels. Dermatology and dermatopathology are impacted by this trend. In particular, the misdiagnosis of melanoma is alleged to account for $13 \%$ of all malpractice claims in the period of 1995$2001 .^{2}$ One study suggested that melanoma was the second most common cause of malpractice litigation in the US. ${ }^{3}$ A survey of 1807 physicians in 1999 showed that $58 \%$ had experienced a medical malpractice claim at some point in their careers. ${ }^{4}$ Although historically pathologists have been at a much lower risk of malpractice litigation than other specialists, lawsuits against pathologists are increasing geometrically as the public becomes more informed about the role of the pathologist in medical care. ${ }^{5}$ Dermatology, in contrast, has a much higher profile and a greater risk of litigation, as the patient is far more familiar with his clinician than with the

Correspondence: Dr AN Crowson, MD, Regional Medical Laboratory, St John Medical Center, 1923 S. Utica Street, Tulsa, OK 74114-4109, USA.

E-mail: ncrowson@sjmc.org

Received 16 September 2005; accepted 28 September 2005 pathologist who was formerly deemed to be in the background of patient care. Those clinicians who practice cosmetic dermatology are at even greater risk. However, the greatest malpractice awards in dermatology have been melanoma claims. ${ }^{6}$ The attendant morbidity and mortality that flow from the mistaken underdiagnosis or nonrecognition of melanoma is the explanation for the latter; the two main causes for melanoma malpractice awards are delay in diagnosis and mistaken diagnosis which most typically represents an error by the histopathologist. $^{7}$

\section{Malpractice, negligence and the burden of proof}

The four standards that must be justified to establish the validity of a medical malpractice claim are duty, breach (ie negligence), proximal cause (ie causation of injury), and damage. ${ }^{1,5,8,9}$ The concept of duty relates to the responsibility of a physician to a patient and flows from the relationship between the patient and their physician. A pathologist who picks up a slide for interpretation and then issues a report at once establishes the relationship between himself and the patient. The duty incumbent upon the pathologist is the accurate, specific and timely reportage of a biopsy or resection specimen. Errors in interpretation or delays in reporting can be 
directly attributable to the pathologist. They may also flow from other events only indirectly under the control of the pathologist, such as typographical errors in the stenographic pool, specimen labeling errors, or substandard or erroneous technical performance at any step in the preparation of the tissue for histological interpretation. The responsibility for the erroneous actions of one or more of his employees who are directly under the control of the pathologist may constitute vicarious liability. ${ }^{9}$ In the event that the pathologist recognizes that poor technical quality may impact his interpretation in a given case and fails to correct the technical deficiency, he may be considered to have exercised negligent supervision. The demonstration of negligence, also termed breach, is the failure to execute the accepted standard of care. Unfortunately, the definitions of breach and of what constitutes an accepted standard of care are so open to interpretation, particularly in jury trials in the US, that the standard may be in constant flux and thus unobtainable. Formerly, breach was defined as a failure to treat within the standard of care $^{1}$ and did not necessarily imply error. Rather, the onus was on the practicing physician to exert a standard of care similar to that which a reasonable, qualified physician in his area would, at that time, have exercised. This local standard is apposite in some states, such as Tennessee. In other jurisdictions, a national standard of care is applied. Expert testimony is typically utilized to define the standard of care in any given malpractice case; $;^{8,10}$ therefore, the opinions or modes and methods of practice of one's peers in the region where one practices may be diluted by said expert testimony. In consequence, the attorneys for both plaintiff and defendant will typically obtain depositions from nationally and/or internationally recognized authorities in a given subspecialty of pathologic practice and, in consequence, disputes arise as to what constitutes the real 'standard of care' in any particular malpractice proceeding. Members of the lay public, and even specialist and subspecialist physicians serving on juries at such trials, may find it impossible to assess said testimony appropriately.

The issue of causation of injury by a particular medical error is termed proximal cause. In essence, it must be established that the failed standard of care has somehow resulted in a patient injury which would not have been sustained had the purported appropriate care been rendered. The final issue is damage, that is, the injury sustained by the patient as a direct result of the error generated by the physician's inability to meet the standard of care. In general terms, all four of the aforementioned issues must be established to be operative by the plaintiff's attorneys or the plaintiff's case will fail. If no injury has been sustained, no intelligent jury will generate an award and no competent attorney will seek a remedy. If an injury has been sustained but cannot be linked to the action of a given physician, the case will be dismissed. The burden of proof upon the plaintiff's attorneys is to show that there is a breach (ie negligence), that that negligence was causative of specific damage, and that an injury was sustained. These issues are not absolute and the onus on the plaintiff's attorneys is thus to establish that a preponderance of the evidence implicates the physician as he relates to the patient, and that his actions as a professional and the damage sustained in consequence by the patient are linked. In attempting to establish these relationships, the plaintiff's attorneys will produce relevant evidence, that is, information intended to prove negligence, causation, and injury. The plaintiff's attorneys cannot present information concerning the record of the defendant, including in the context of previous medicolegal action against him. In contrast, the records of the expert witnesses may be evidentiary.

Only about one in 30 calls from patients to legal firms eventuate in a lawsuit ${ }^{8}$ and most of these lawsuits do not generate indemnity payments. ${ }^{1,11,12}$ Tort reform, when the result of effective and welldesigned legislation, has a tendency to reduce malpractice damage awards and consequently to reduce the cost of medical malpractice insurance. In particular, those states that have imposed hard caps on noneconomic damages (ie pain and suffering of patients and their families) experience a reduction in insurance premiums and also in the number of medical malpractice claims. It has been suggested that attorneys in such states find the financial rewards of malpractice litigation less satisfying and in consequence are less apt to encourage their clients to litigate. ${ }^{11,13}$

In Canada, a national organization, the Canadian Medical Protective Association (CMPA) insures virtually all physicians in the country, has a strong financial reserve and repeatedly uses the same limited number of malpractice attorneys in each major center. In consequence, the expertise of defense attorneys is high compared to that of attorneys representing the plaintiff in a typical malpractice lawsuit. The number of medical malpractice claims per capita in Canada, along with the size of the indemnity awards, is vastly lower than is seen in the US. However, owing to the more litigious climate in the US, CMPA may refuse to insure a Canadian physician involved in a malpractice claim resulting from services rendered to an American citizen.

\section{The nature of error in dermatopathological practice}

In the laboratory, errors can occur in any of the preanalytical, the analytical, or the postanalytical phases. This applies to anatomical as well as to clinical laboratory practice. With respect to anatomical pathology, preanalytical errors include the 
quality of the biopsy sample (ie inadequate size, crush artefact, or choice of a biopsy site that does not adequately represent the lesion), mishandling or mislabeling of a specimen in the gross dissection room, poor technical quality, or loss of the tissue element, prior to its receipt on the desk of the pathologist who will interpret the case. Analytical errors are typically errors of interpretation: the pathologist fails to recognize clues to diagnosis, missing important findings which impact classification or prognosis, or misinterprets specific findings needed to arrive at a correct case construction. Reports which are unequivocal on suboptimal biopsies or which imply certainty where uncertainty exists, and therefore lack caveats concerning the limits of interpretation of the case, are another source of concern. The key question is whether the resulting report generates or, in the hands of a clinician exercising an adequate standard of care, ought to generate appropriate therapy for the patient. Postanalytic errors include, among others, stenographic errors in the report such as key typographical errors, misidentification of site or patient, and the failure to transmit the report to the clinician.

Several different types of neoplastic skin lesions have been the source of medicolegal action. Of these, as mentioned above, melanocytic neoplasms are by far the most common. Glusac ${ }^{1}$ describes 'four principles' that underlie this fact. First, melanocytic neoplasms are said to be perhaps the most common neoplasms in human beings. Second, melanoma is, by size, arguably the most lethal human neoplasm. That is, at a similar size of a few millimeters, a cancer of thyroid, breast, or colon is unlikely to even be discovered or, if discovered, is often eminently curable by simple excision. A melanoma of a few millimeters in diameter, if in vertical growth phase, may kill. ${ }^{14}$ Third, the distinction between melanoma and nevus can be challenging at the light microscopic, and even at the molecular level ${ }^{15,16}$ just as it is at the clinical level. ${ }^{17,18}$ Various studies have shown that even expert melanocytic lesion pathologists are unable to obtain a concordant view on one-quarter to two-thirds of studied lesions. ${ }^{19,20}$ These figures vary with the subset of melanocytic lesions under discussion, with the particularly treacherous Spitzoid melanomas and atypical Spitz's tumors generating the least consensus. ${ }^{21}$ With respect to the latter, Barnhill et $a l^{21}$ demonstrated a lack of consensus among members of an expert panel for 17 of 30 cases; 13 of 21 lesions held to be Spitz tumors metastasized. Another group showed sentinel lymph node parenchymal metastases in five of 10 patients with Spitzoid lesions. ${ }^{22}$ In our hands and in the experience of others, predicting a malignant phenotype in melanocytic proliferations in childhood is particularly challenging. ${ }^{23}$ The fourth consideration is that melanoma, as it is a disease of young as well as old patients, has the potential to cause great loss of life with attendant social and economic disruption for the family members of the deceased, as it results in more lost years of life per case fatality than any other neoplastic disorder, except perhaps leukemia. ${ }^{1,24}$

\section{Underdiagnosis}

With respect to the underdiagnosis of melanoma, several factors can increase the risk of such events. First of all, as mentioned above, partial samples of melanocytic tumors may fail to represent the most aggressive morphology in any given lesion. ${ }^{25}$ Crush artefact can obscure the morphology and, in the case of heavily inflamed melanocytic proliferations, the inflammatory reaction itself can obscure the cytology of the neoplastic melanocytes. The clinician may choose the wrong area to biopsy; in particular, a pre-existing dysplastic or banal common acquired nevus in the territory of a superimposed melanoma may be the only portion of the lesion sampled. In contrast, areas of whitish discoloration representing regression may be sampled without the accompanying neoplastic melanocytes necessary to establish the histologic diagnosis. Crush and cautery artefact also obscure morphological detail.

The second problem in underdiagnosis of melanoma is represented by those melanocytic proliferations that mimic benign nevi. In particular, nevoid melanoma, ${ }^{26-33}$ minimal deviation melanoma, ${ }^{26,34-39}$ desmoplastic melanoma, ${ }^{3,40-45}$ and the atypical spitzoid melanocytic proliferations ${ }^{21,33}$ represent special problems in melanocytic tumor pathology.

With respect to the aforementioned specific scenarios, some of them have a repeating theme. The first is that of the nodular melanoma misdiagnosed as a nevus. The clinician will often report a 'changing nevus' which by itself may have none of the specific atypical 'ABCD' features-that is, asymmetry, irregular border, peculiar or irregular coloration, or large diameter (ie greater than $6 \mathrm{~mm}$ ). In particular, nevoid melanoma and the so-called minimal deviation melanoma both manifest as changing lesions in the setting of pre-existing, often long-standing, melanocytic nevi. We have also seen several cases, in childhood, of combined nevi or long-standing Spitz tumors undergoing malignant degeneration, including in the context of metastases in sentinel and nonsentinel lymph nodes. As malignant change may be local and focal within a particular neoplasm, step sections are often a useful adjunct in the setting of a changing melanocytic nevus. It is essential, however, that the clinician provides this history with submission of the biopsy. Clinicians are counseled equally to be aware of discordance between their clinical impression and the pathology report. ${ }^{2}$ Communication between clinician and pathologist is an essential aspect of patient care and also an important line of defense for them and their patients. Most of us have had the 
personal experience of a telephone call from an experienced clinician requesting step levels to exclude a melanoma in a pre-existing dysplastic nevus, only to find that, in fact, deeper levels through the block showed the fully developed cancer which was not apparent at the time the report was generated. Of all melanoma claims, it is suggested that over $80 \%$ involve shave, punch, or incisional biopsies, while fewer than $20 \%$ involve complete excisions. ${ }^{2}$ The ideal melanocytic tumor biopsy is one which encompasses the entire lesion plus a $2-3 \mathrm{~mm}$ margin of adjacent normal skin. If a melanoma is detected and the depth is sufficient to merit sentinel lymph node biopsy, the procedure can still be performed as the lymphatic bed of the neoplasm has not been so perturbed as to produce a disordered pattern of lymphatic drainage. Not only is a proper diagnosis facilitated by a complete excisional biopsy, but prognostic microstaging, as described elsewhere in this Supplement, is far more likely to be accurate in a fully excised lesion.

Another frequent medicolegal case scenario is that of a melanoma diagnosed as a dysplastic nevus with positive margins. This is an area which is in flux. Formerly, we did not recommend complete excision of partially excised dysplastic nevi if only mild cytologic and architectural atypia was present. ${ }^{33}$ However, most of us have had the experience of a subsequent late recurrence of an incompletely excised mildly dysplastic nevus and/or progression to melanoma at that location. If a clinician opts not to re-excise a dysplastic nevus with positive margins, the patient must be counseled to promptly report any recurrent or residual pigmented lesion at that location. Clinical follow-up is thus of paramount importance.

The fourth case scenario is that of melanoma misdiagnosed as a Spitz's nevus. Spitz nevi are aneuploid in roughly $25 \%$ of cases. ${ }^{33}$ Which nevi are aneuploid, and thus biologically unstable, cannot be determined by light microscopy alone. Our practice, therefore, is to advise complete excision of all Spitz's nevi with only rare exceptions. Such exceptions would include those that would require mutilating surgery or functional compromise of anatomical structures, especially in young children. Some dermatologists would dispute this recommendation as being excessive, but most would not argue that any Spitzoid neoplasm in an adult should not be completely excised.

The fifth case scenario is that of the desmoplastic melanoma, misinterpreted clinically and pathologically as a scar or dermatofibroma.

The sixth case scenario is that of a patient who presents with metastatic melanoma of unknown primary site only to recall the removal and discard or destruction of a skin lesion in the past. Any and all pigmented skin lesions removed from a patient should be submitted for histopathological analysis. One could make the argument that pedunculated skin tag-like lesions with no suggestion of pigmentation should also be submitted for histology, in light of the danger of missing a verrucous nevoid melanoma.

Owing to the time delay between the underdiagnosis of melanoma and the subsequent recurrence and/or metastatic events and their evaluation, diagnosis, therapy and outcome, litigation in cases of underdiagnosed melanoma typically takes 3-10 years to mature.

\section{Overdiagnosis}

The opposite problem is overdiagnosis with excessive therapy; this can include mutilating surgical procedures and/or adjuvant therapy. The latter includes interferon alpha therapy, which has potential toxic side effects. The advent of the sentinel lymph node biopsy, which causes little in the way of functional impairment, including in the context of lymphedema, has lessened the impact of unnecessary lymph node dissection in overdiagnosed melanocytic lesions. In consequence, the sentinel lymph node biopsy is held by some observers to have a role in establishing the metastatic potential of any given 'borderline' or prognostically indeterminate melanocytic proliferation. ${ }^{33}$

Certain types of lesions are particularly prone to be the source of an overdiagnosis of melanoma. The effect of ultraviolet irradiation on promoting melanocyte activation, and the impact or psoralens and plant products such as in the setting of phytophotodermatitis or psoralen with ultraviolet light (PUVA) therapy are two such pitfalls. ${ }^{46,47}$ Another is the histologic appearance of nevi of peculiar anatomic sites (ie milk line, flexural, auricular, genital, or acral nevi). ${ }^{3348,49}$ All may generate a histomorphology suspicious for melanoma. ${ }^{50}$ Other potential pitfalls for overdiagnosis include the pigmented spindle cell nevus and the combined nevus, including in the context of the deep penetrating nevus. With respect to the deep penetrating/inverted type $\mathrm{A}$ nevus and its combined nevus variant, our policy, based upon sobering experience, is to recommend complete excision of all such lesions. As overdiagnosis is only detected through peer case review, such events often go unappreciated by the clinician and the patient.

From the standpoint of nonmelanocytic neoplasms, which represent a potential medicolegal pitfall, the misclassification of basal cell carcinoma and a failure to recognize infiltrative neoplasms such as microcystic adnexal carcinoma, squamous cell carcinoma (particularly in the case of neurotropism), and atypical intraepithelial proliferations, such as clonal Bowen's disease and porocarcinoma in situ, are all potential pitfalls. In addition to the foregoing, inaccurate interpretation of margins has been a source of medicolegal action. 


\section{Strategies for the avoidance of potentially litigious diagnostic errors}

Several caveats flow from the above considerations. First and foremost, proper and full communication between pathologist and clinician is essential. The pathology requisition must be fully and accurately documented in terms of the patient's name, age, sex, the site of the biopsy, and the clinical concerns. The 'chain of control' of the biopsy from the clinician's office through the courier system to the pathology gross laboratory must be intact and must utilize a verifiable regimen for specimen tracking. The gross laboratory prosector, either pathologist or pathologist's assistant, should be fully acquainted with the proper methods of handling and description of specimens. The histopathology laboratory requires equipment that is well maintained to ensure adequate tissue processing. Histotechnologists of experience and capability are necessary to provide good sections. With respect to specimen embedding and paraffin blocks, the pieces of tissue must be close enough together to facilitate good sectioning and also to help ensure that the pathologist does not fail to examine a tissue element. ${ }^{1}$ Secondly, if too many tissues elements are incorporated into the tissue cassette prior to paraffin embedding, orientation of the tissue elements by the histotechnologist is compromised, and microscopic interpretation becomes more difficult. Similarly, the orientation of the tissue elements to the block face by an experienced histotechnologist will help to avoid tangential sections, which may compromise interpretation and also make accurate Breslow thickness measurements difficult or impossible. Incomplete sections are problematic not only for margin assessment but also for evaluation of features essential to the diagnosis of melanoma. Small punch or shave biopsies (ie $3 \mathrm{~mm}$ in transverse diameter), when embedded as single tissue elements and then sectioned, may not adequately represent a pigmented lesion, which presumably is roughly central in the biopsy. Correlation with the clinical impression is, therefore, essential to ensure that if a dysplastic nevus was suspected, appropriate step levels were cut through the block to identify the territory of interest. Curettage biopsies of melanocytic neoplasms are not recommended due to fragmentation and misorientation of the tissue elements. ${ }^{1}$ Most of us are familiar with examples of misdiagnosis in curetted melanocytic proliferations.

Even when all of the aforementioned steps are taken correctly and the quality of histotechnology is high, certain cases will prove problematic, even to the most experienced, compulsive, astute, and talented histopathologist. The question arises as to what one ought to do when confronted with a biopsy which defies precise classification and represents a prognostically indeterminate nevomelanocytic proliferation. Our strategy for the reporting of such prognostically indeterminate nevomelanocytic pro- liferations has been described elsewhere in some detail. ${ }^{33}$ Simply put, our intention is to express our uncertainty about the prognostic attributes of a neoplasm in the pathology report. We believe that the patient is best served when a prognostically indeterminate nevomelanocytic proliferation is treated as though it were melanoma, including in the context of sentinel lymph node biopsy. The latter is a nonmutilating procedure with limited associated morbidity ${ }^{51}$ which has been traditionally reserved for melanomas in the 1-4 $\mathrm{mm}$ depth range, or those tumors less than $1 \mathrm{~mm}$ in thickness that show either a vertical growth phase component or substantial regression at the primary site. Unfortunately, no significantly beneficial adjuvant therapy has been demonstrated for melanomas greater than $4 \mathrm{~mm}$ in depth or those with distant metastases. The largest series available suggests that completion lymphadenectomy for patients with positive sentinel lymph node deposits produces a statistically significant survival benefit, as opposed to those patients in whom there was a delay for completion lymphadenectomy following a positive sentinel lymph node while clinicians waited for clinically evident lymph node metastases. Our diagnostic strategy, therefore, is to proceed to completion lymphadenectomy when prognostically significant sentinel lymph node deposits are identified in the sentinel lymphadenectomy specimen (see Prognosticators of Melanoma in this Supplement).

Our second strategy is to liberally obtain additional opinions. Obtaining one or more additional opinions of experienced and skilled melanocytic tumor pathologists is a critical component of due diligence. It also shows to the referring clinician and to the patient and his or her family that an effort has been made in good faith to arrive at the best possible diagnosis. For the most challenging melanocytic proliferations, and in particular, for those in children, we invariably put two or more signatures to the pathology report and frequently seek expert outside consultative opinion.

The more frequent scenario in litigation following underdiagnosis of melanoma is that a lesion with a metastatic potential has been considered to be benign without any equivocation or caveats applied in the pathology report. To prevent such events without a $100 \%$ review policy would be impossible. Thus, at Regional Medical Laboratory in Tulsa, OK, $100 \%$ of all anatomic pathology reports with the complete slides from the case are reviewed by a second pathologist and tracked in a complex computerized database. While the turnaround time standard for the primary report ranges from 24 to $48 \mathrm{~h}$, depending upon the nature of the specimen, the turnaround time standard for the review system is currently $72 \mathrm{~h}$. Thus, within a maximum of five business days after receipt of the specimen, two pathologists will have reviewed the case and their opinions will have been recorded in an electronic database. The intent of review is to avoid the 
Table 1 Results of surgical pathology review in a general hospital in Oklahoma

\begin{tabular}{lccc}
\hline & $\begin{array}{c}\text { \# Surgical } \\
\text { reports }\end{array}$ & $\begin{array}{c}\text { \# Significant } \\
\text { errors }\end{array}$ & $\begin{array}{c}\text { \# Insignificant } \\
\text { errors }\end{array}$ \\
\hline May 2000-October 2000 & 4227 & 3 & 9 \\
November 2000-April & 3965 & 2 & 9 \\
2001 & & & \\
May 2001-October 2001 & 4237 & 3 & 15 \\
November 2001-April & 3972 & 2 & a \\
2002 & & & \\
May 2002-October 2002 & 3969 & 4 & 3 \\
November 2002-April & 3634 & 2 & 2 \\
2003 & & & \\
May 2003-October 2003 & 3819 & 0 & 0 \\
November 2003-April & 4068 & 3 & a \\
2004 & & & 9 \\
May 2004-October 2004 & 3865 & 6 & 47 \\
Total & 35756 & 25 & \\
\hline
\end{tabular}

${ }^{\mathrm{a}}$ Not recorded.

complication of underdiagnosis, namely metastatic disease in an unsuspecting patient. Rapid correction of errors with immediate verbal communication to the clinician and the subsequent generation of a revised report documenting both the error and the time and date of the direct notification of the clinician ensues. This form of $100 \%$ review is laborious, expensive, and time consuming. ${ }^{52}$ Detection of clinically significant diagnostic errors by systems such as this are reported to be in the range of $0.26-1.7 \% .^{52-55}$

A representative sample of data from a laboratory utilizing a $100 \%$ review system is provided in Table 1. The data presented cover a period of 54 months, from May 2000 to October 2004. Of 35,756 reports generated at that facility, significant errors were identified in 25 reports $(0.070 \%$ of cases). A significant error is defined as one that, if left uncorrected, has the potential to generate an adverse patient outcome. Insignificant errors constitute those mistakes, such as, for example, typographical miscues that do not alter the substance of the report and which, if corrected, would not alter patient care. The insignificant error rate was approximately 2.4 times that of the significant error rate. Not shown in these data, and undefinable in such systems, are those errors which were made in the original surgical pathology report and not detected in the review process.

\section{Conclusion}

Medical malpractice litigation is a significant factor impacting health care costs, insurance rates, affordability, and availability of care in the US and Canada. Various factors historic, legal, and financial make this problem far more serious in the US. Tort reform has the capacity and potential to alleviate the burden of medicolegal cost to the system and to practitioners, but it is no panacea. A free and honest communication flow between clinician and pathologist, rigorous control of the tissue trail from the clinician's office to the laboratory, comprehensive quality assurance mechanisms in the gross and histopathology laboratories, careful pathological interpretations that recognize the limitations of the art and science, which we apply to our discipline, and a comprehensive review system that is open and transparent to clinical practitioners are the best lines of defense in a litigious environment.

\section{Acknowledgements}

I am indebted to Dr CT Dolan of Regional Medical Laboratory in Tulsa, OK, and Mr RL Sewell of Short, Wiggins, Margo and Adler in Oklahoma City for their kindness in reviewing this manuscript.

\section{References}

1 Glusac EJ. Under the microscope: doctors, lawyers, and melanocytic neoplasms. J Cutan Pathol 2003;30: 287-293.

2 Sullivan M. How to protect yourself from melanoma claims. Skin Allergy News 2005;April:24-25.

3 Troxel DB, Sabella JD. Problem areas in pathology practice. Uncovered by a review of malpractice claims. Am J Surg Pathol 1994;18:821-831.

4 Forster J (ed). Malpractice survey snapshot: who's been sued-and who won. Med Econ 1999;76:58-60, 65, 69.

5 Epstein JI. Pathologists and the judicial process: how to avoid it. Am J Surg Pathol 2001;25:527-537.

6 Altman J. The National Association of Insurance Commissioners (NAIC) medical malpractice closed claim study 1975-1978. J Am Acad Dermatol 1981;5: 721-725.

7 Jackson R. Malignant melanoma: a review of 75 malpractice cases. Int J Dermatol 1997;36:497-498.

8 Gittler GJ, Goldstein EJC. Medicolegal case reviews. Clin Infect Dis 1996;23:1152-1155.

9 Martello J. Basic medical legal principles. Clin Plast Surg 1999;26:9-14.

10 Petrek Jr FR, Slovis MR. The defendant in a medical malpractice suit: an integral part of the defense team. Pediatr Radiol 1998;28:905-912.

11 Ellington DP, Rosenthal RS. The defense perspective. Med Malpractice 1997;94:323-327.

12 Moran T. So you've been sued. Tips for enduring and avoiding the malpractice roller coaster ride. Tex Med 1995;91:24-31.

13 Zuckerman S, Bovbjerg RR, Sloan F. Effects of tort reforms and other factors on medical malpractice insurance premiums. Inquiry 1990;27:167-182.

14 Clark Jr WH, Elder DE, Van Horn M. The biologic forms of malignant melanoma. Hum Pathol 1986;17:443-450.

15 Piepkorn M, Odland PB. Quality of care in the diagnosis of melanoma and related melanocytic lesions. Arch Dermatol 1997;133:1393-1396.

16 Smith KJ, Barrett TL, Skelton HG. Spindle cell and epithelioid cell nevi with atypia and metastasis 
(malignant spitz nevus). Am J Surg Pathol 1989;13: 931-939.

17 Grant-Kels JM, Bason ET, Grin CM. The misdiagnosis of malignant melanoma. J Am Acad Dermatol 1999; 40:539-548.

18 Andersen WK, Silvers DN. Melanoma? It can't be melanoma!' A subset of melanomas that defies clinical recognition. JAMA 1991;266:3463-3465.

19 Farmer ER, Gonin R, Hanna MP. Discordance in the histopathologic diagnosis of melanoma and melanocytic neoplasms between expert pathologists. Hum Pathol 1996;27:528-531.

20 Corona R, Mele A, Amini M, et al. Interobserver variability on the histopathologic diagnosis of cutaneous melanoma and other pigmented skin lesions. J Clin Oncol 1996;14:1218-1223.

21 Barnhill RL, Argenyi ZB, From L, et al. Atypical spitz nevi/tumors; lack of consensus for diagnosis, discrimination from melanoma, and prediction of outcome. Hum Pathol 1999;30:513-520.

22 Lohmann CM, Coit DG, Brady MS, et al. Sentinel lymph node biopsy in patients with diagnostically controversial spitzoid melanocytic tumors. Am J Surg Pathol 2002;26:47-55.

23 Wechsler J, Bastuji-Garin S, Spatz A, et al. Reliability of the histopathologic diagnosis of malignant melanoma in childhood. Arch Dermatol 2002;138: $625-628$.

24 Albert VA, Koh HK, Geller AC, et al. Years of potential life lost: another indicator of the impact of cutaneous malignant melanoma on society. J Am Acad Dermatol 1990;23:308-310.

25 Troxel DB. Diagnostic errors in surgical pathology uncovered by a review of malpractice claims. Part IV. Melanoma. Int J Surg Pathol 2001;9:61-63.

26 Philips ME, Margolis RJ, Merot Y, et al. The spectrum of minimal deviation melanoma: a clinicopathologic study of 21 cases. Hum Pathol 1986;17:796-806.

27 Suster S, Ronnen M, Bubis JJ. Verrucous pseudonevoid melanoma. J Surg Oncol 1987;36:134-137.

28 Wong TY, Duncan LM, Mihm Jr MC. Melanoma mimicking dermal and Spitz's nevus ('nevoid melanoma'). Semin Surg Oncol 1993;9:188-193.

29 McNutt NS, Urmacher C, Hakimian J, et al. Nevoid malignant melanoma: morphologic patterns an immunohistochemical reactivity. J Cutan Pathol 1995;22: 502-517.

30 Wong TY, Suster S, Duncan LM, et al. Nevoid melanoma: a clinicopathological study of seven cases of malignant melanoma mimicking spindle and epithelioid cell nevus and verrucous dermal nevus. Hum Pathol 1995;26:171-179.

31 Kossard S, Wilkinson B. Small cell (naevoid) melanoma: a clinicopathologic study of 131 cases. Australas J Dermatol 1997;38(Suppl 1):S54-S58.

32 Blessing K, Grant JJ, Sanders DS, et al. Small cell malignant melanoma: a variant of naevoid melanoma. Clinicopathological features and histological differential diagnosis. J Clin Pathol 2000;53:591-595.

33 Crowson AN, Magro CM, Mihm Jr MC. The Melanocytic Proliferations: a Comprehensive Textbook of Pigmented Lesions. John Wiley and sons: New York, 2001, pp 281-397.
34 Muhlbauer J, Margolis R, Mihm MC, et al. Minimal deviation melanoma: a histologic variant of cutaneous malignant melanoma in vertical growth phase. J Invest Dermatol 1983;80:63s-65s.

35 Philips ME, Margolis RJ, Merot Y, et al. Common and uncommon melanocytic nevi and borderline melanomas. Semin Oncol 1975;2:119-147.

36 Reed RJ. Minimal deviation melanoma. Hum Pathol 1990;21:1206-1211.

37 Reed RJ, Martin P. Variants of melanoma. Semin Cutan Med Surg 1997;16:137-158.

38 Reed RJ. Minimal deviation melanoma. Borderline and intermediate melanocytic neoplasia. Clin Lab Med 2000;20:745-758.

39 Podnos YD, Jimenez JC, Zainabadi K, et al. Minimal deviation melanoma. Cancer Treat Rep 2002;28: 219-221.

40 Conley J, Lattes R, Orr W. Desmoplastic malignant melanoma (a rare variant of spindle cell melanoma). Cancer 1971;28:914-936.

41 Bruijn JA, Mihm Jr MC, Barnhill RL. Desmoplastic melanoma. Histopathology 1992;20:197-205.

42 Skelton HG, Smith KJ, Laskin WB, et al. Desmoplastic malignant melanoma. J Am Acad Dermatol 1995;32: 717-725.

43 Carlson JA, Dickersin GR, Sober AJ, et al. Desmoplastic neurotropic melanoma. A clinicopathologic analysis of 28 cases. Cancer 1995;75:478-494.

44 Egbert B, Kempson R, Sagebiel R. Desmoplastic malignant melanoma. A clinicopathologic study of 25 cases. Cancer 1988;62:2033-2041.

45 LeBoit PE, Ming ME. Litigious melanocytic proliferations and how to avoid them. Pathol Case Rev 1999;4: 77-86.

46 Tronnier M, Wolff HH. UV-irradiated melanocytic nevi simulating melanoma In Situ. Am J Dermatopathol 1995;17:1-6.

47 Somach SC, Taira JW, Pitha JV, et al. Pigmented lesions in actinically damaged skin. Histopathologic comparison of biopsy and excisional specimens. Arch Dermatol 1996;132:1297-1302.

48 LeBoit PE. A diagnosis for maniacs. Am J Dermatopathol 2000;22:556-558.

49 Rongioletti F, Ball RA, Marcus R, et al. Histopathological features of flexural melanocytic nevi: a study of 40 cases. J Cutan Pathol 2000;27:215-217.

50 Kerl H. Pseudomelanomas: pitfalls in the diagnosis of malignant melanoma. Am J Dermatopathol 1992;14:75.

51 Morton DL, Cochran AL, Thompson JF, et al. Sentinel node biopsy for early-stage melanoma. Ann Surg 2005;242:302-313.

52 Safrin R, Bark C. Surgical pathology signout. Routing review of every case by a second pathologist. Am J Surg Pathol 1994;17:1190-1192.

53 Lind A, Bewtra C, Healy JC, et al. Prospective peer review in surgical pathology. Am J Clin Pathol 1995; 104:560-566.

54 Abt A, Abt L. The effect of interinstitutional anatomic pathology consultation on patient care. Arch Pathol Lab Med 1995;119:514-517.

55 Wakely S, Baxendine-Jones J, Gallagher PJ, et al. Aberrant diagnoses by individual surgical pathologists. Am J Surg Pathol 1998;22:77-82. 